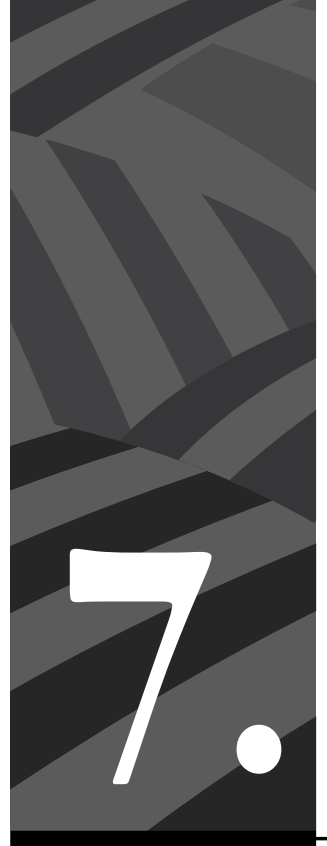

El 'baculazo a la gobernadora': Mujeres, género y política en Colombia en la década del setenta del siglo $\mathrm{XX}$ 


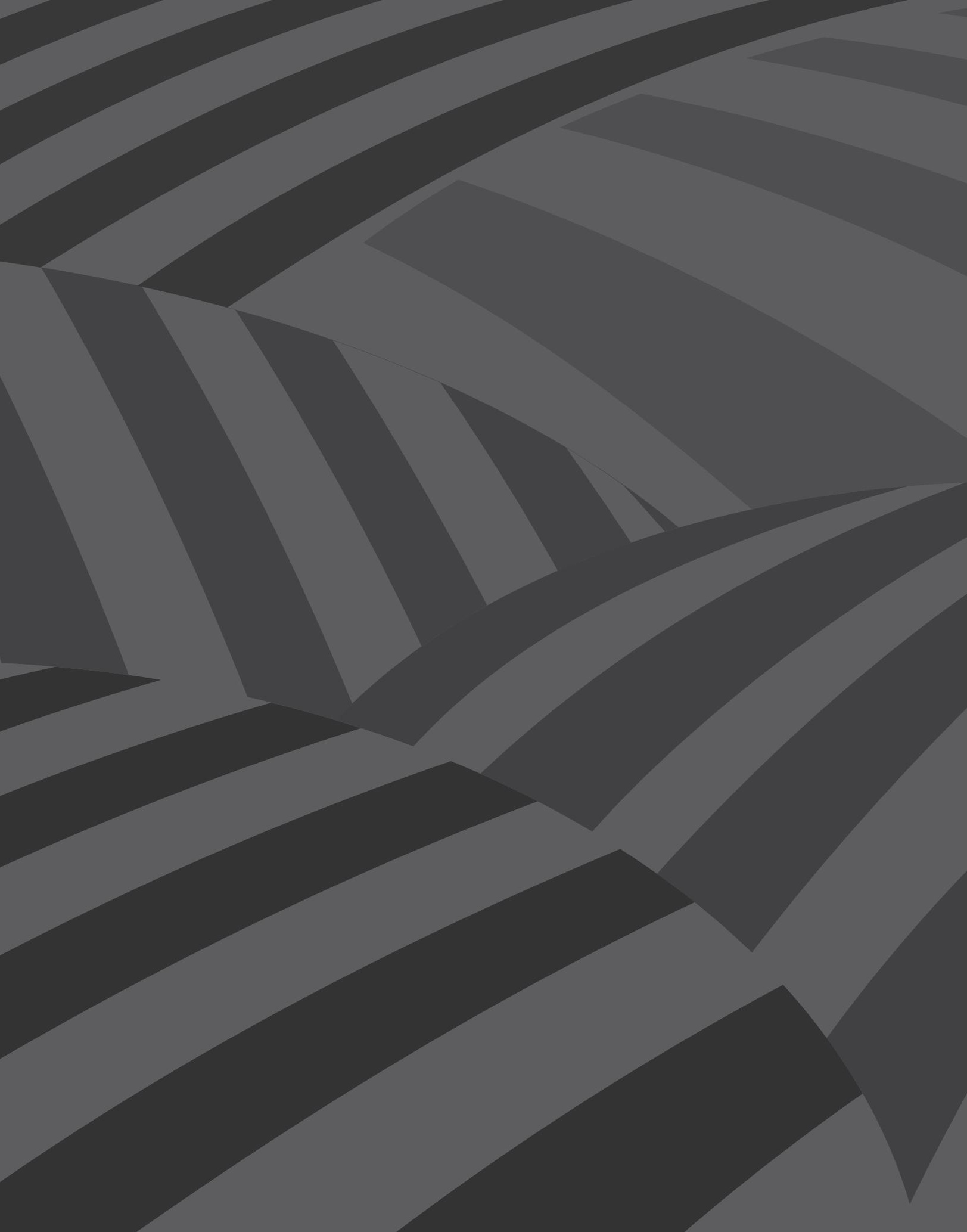




\title{
El 'baculazo a la gobernadora': Mujeres, género y política en Colombia en la década del setenta del siglo XX
}

\author{
Por Juan Camilo Pantoja García*, Girlandrey Sandoval Acosta**
}

Resumen: En febrero de 1975, el presidente Alfonso López Michelsen nombró gobernadora del departamento de Risaralda a Dora Luz Campo. Los obispos de Pereira, capital de Risaralda, vetaron esa decisión aduciendo razones morales, ya que ella, luego de estar casada por lo católico, se divorció y volvió a casar por lo civil con otra persona. En este artículo se analizan las representaciones de género que circularon en la prensa en torno a este episodio, con el objetivo de mostrar cómo el orden de género se produce, refuerza y transforma en contextos específicos. Este episodio dejó ver que la concepción de la jerarquía católica sobre las reglas formales e implícitas a las que, en su concepto, debían ajustarse las mujeres que entraban a ocupar cargos públicos habían perdido influencia y eran desafiadas por otra, presentada como más moderna, pero con sus límites: la de un orden de género que reproducía y reforzaba los ideales de maternidad y fragilidad femenina.

Palabras clave: política, mujeres, orden de género, roles de género, estereotipos de género.

\section{The 'baculazo a la gobernadora': Women, Gender, and Politics in Colombia during the 1970s}

Abstract: In February 1975, the president of Colombia, Alfonso López Michelsen (liberal) appointed Dora Luz Campo de Botero as governor of the department of Risaralda. The bishops of Pereira (capital of Risaralda) veto that decision adducing moral reasons because after being married by the Catholic Church she separated and then had another civil marriage. This article

* Historiador por la Universidad Nacional de Colombia y maestro en Ciencia Política por el Colegio de México, doctorando en Historia por la misma institución. Su línea de trabajo está relacionada con la cultura política y las consecuencias de la violencia, tanto política como criminal, en los procesos de construcción de Estado nacional y subnacional. Correo electrónico: jpantoja@colmex.mx

** Historiadora por la Universidad del Valle (Cali, Colombia); maestra en Sociología por FlaCSO (Quito, Ecuador); y especialista en Estudios Feministas y de Género por la Universidad Nacional de Colombia (Bogotá). Docente e investigadora en la Corporación Universitaria Minuto de Dios, sede Bogotá. Correo electrónico: gsandoval@unal.edu.co 
analyzes the gender representations that circulated in the press around this episode in order to show how the gender order is produced, reinforced and transformed in particular contexts. This episode made visible that the conception of the colombian catholic hierarchy about the gender order to which women that were seeking to occupy high ranking public posts were expected to adjust was loosing authority, and was being challenged by another conception, presented as modern, but that had its own limits, because those women were expected to adjust to a gender order that reproduced and reinforced the ideals of maternity and femininity.

Keywords: politics, women, gender order, gender roles, gender stereotypes.

Cómo citar este artículo: Pantoja García, Juan Camilo; Sandoval Acosta, Girlandrey (2020). El 'baculazo a la gobernadora': Mujeres, género y política en Colombia en la década del setenta del siglo xx. Revista Controversia, 215, 237-275.

Fecha de recepción: 20 de marzo de 2020

Fecha de aprobación: 20 de julio de 2020

\section{Introducción}

728 de febrero de 1975, el presidente de Colombia, Alfonso López Michelsen (liberal), nombró gobernadora del departamento de Risaralda a Dora Luz Campo (El Espectador, 1975b, p. 5A). Al día siguiente, los obispos de Pereira (capital de Risaralda) Baltazar Álvarez y Darío Castrillón enviaron un telegrama al presidente López vetando dicho nombramiento y pidiéndole que designara a otra persona en dicho cargo. En su telegrama, los obispos explicaban que el veto se debía a que el "comportamiento social [de Dora Luz Campo] ofende [los] sentimientos cristianos y [la] dignidad del pueblo risaraldense" (El Espectador, 1975c, pp. 1A y 20A). El comportamiento social que los prelados criticaban hacía referencia a que Dora Luz Campo se casó por lo católico, se divorció y se volvió a casar por lo civil en el extranjero. A pesar del apoyo que recibió por parte de sectores de la prensa, del Gobierno, del mundo político, de grupos de mujeres, de su familia y de actores individuales, el episodio terminó cuando Dora Luz Campo desistió de aceptar el nombramiento que le permitía ocupar la Gobernación (El Espectador, 1975r, p. 5A). 
Este episodio, denominado por la prensa 'el baculazo a la gobernadora', permitió la circulación de discursos de género propios de la época y el reconocimiento, a su vez, de las transformaciones del ideal femenino de mediados del siglo xx, a través del posicionamiento de la idea de "la

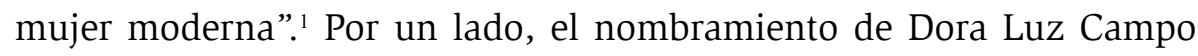
daba cuenta de una mayor apertura hacia las mujeres en ciertos espacios masculinizados y, por el otro, el veto de los obispos reflejaba la reacción de sectores de la sociedad que buscaban reforzar o mantener inalterado un orden social basado en el ideal tradicional de la familia católica, según el cual la mujer debía ajustar su comportamiento a los preceptos de la Iglesia, y en este caso específicamente a lo preceptuado respecto al sagrado sacramento del matrimonio. En este contexto, la inclusión de mujeres en cargos políticos reservados principalmente para los hombres implicaba romper ciertos límites de género. Sin embargo, en el caso de Dora Luz Campo dichas limitaciones se ampliaron a la condición socioeconómica, pues las mujeres que por entonces ocupaban cargos públicos en su mayoría eran de clase alta o media alta y estaban conectadas con hombres en altos cargos políticos o empresariales; también al rol social que les correspondía a las mujeres según el orden de género vigente, aliado de los discursos de género católicos y conservadores. En otras palabras, el 'baculazo a la gobernadora' representó los discursos tradicional y moderno sobre la mujer colombiana en la década del setenta, y mostró tanto los avances como los límites del ideal republicano de igualdad entre los sexos.

1 La expresión "mujer moderna" hace referencia, en el lenguaje de la época de "El baculazo", a la transformación de roles y estereotipos de género impuestos a las mujeres en Colombia y que a mediados del siglo xx les obstaculizaban el ejercicio de derechos jurídicos-formales. María Lugones (2008) afirma que la imposición del proyecto moderno en América Latina tiene que ver con dos procesos: la colonialidad del poder y la colonialidad del género. El discurso de la "mujer moderna" en el siglo xx en Colombia está profundamente atravesado por estos elementos mencionados por Lugones. De modo que la invención de la locución "mujer moderna" representa una transición en los roles de género de la época, basados en una visión de la mujer blanca, heterosexual, clase media-alta, consumidora y judeo-cristiana por excelencia, que ejerce derechos políticos en tanto goza de los privilegios de la relación clase-raza-religión. 
De este modo, el binomio mujeres-política nos permite identificar las representaciones sociales de género que circularon en Colombia en un momento histórico concreto, así como parte del devenir histórico de su lucha por la consecución de derechos civiles y políticos. Los trabajos de Magdala Velásquez, y especialmente su manuscrito conjunto con Catalina Reyes Cárdenas, evidencian la antesala del discurso de la Iglesia entre los años cuarenta y cincuenta:

El Papa Pío XII fue bastante prolífico en sus discursos escritos sobre la mujer y la familia (...) trataba de hacer (...) una combinación doctrinaria que mantuviera la sujeción de la mujer al marido, y al mismo tiempo reivindicaba el reconocimiento de sus derechos políticos. (Velásquez y Reyes, 1995, p. 231).

El arreglo de dichos discursos, valores e imaginarios se corresponde con el orden de género de la época, es decir, la forma como se produce y se construye el género en una forma culturalmente específica (Connel y Pearse, 2018, p. 47).

De esta manera, en este trabajo se insistirá en la definición que Joan Wallach Scott (2003, p. 56) teoriza sobre el género:

Una categoría útil para el análisis histórico, en tanto hace manifiesta la relación de poder inmersa en la diferencia sexual (...) el género comprende un orden simbólico normativo, el cual posee nociones políticas que circulan en todos los escenarios de la vida social y que construye identidades subjetivas de manera histórica. (2003, p. 56).

Es decir, entendemos el género como una forma de ordenamiento de la práctica social, por supuesto, del imaginario de época en un contexto político. Nos interesa particularmente el hecho histórico en el que se configura la práctica, en este caso de la participación en política de un tipo de mujer muy particular, en un escenario que se está reconfigurando en Colombia posterior al periodo del Frente Nacional, y que da 
cuenta de un modo de gestión y producción del género con escalas y estilos contradictorios.

El propósito de este trabajo es examinar, a partir de la representación que de este episodio hizo la prensa, por un lado, la contradicción entre la apertura de mayores espacios de participación pública de las mujeres y la reacción de ciertos sectores tradicionales encabezados por la alta jerarquía católica del país; y, por el otro, las limitaciones del discurso que apoyaba el ingreso de más mujeres a espacios que, como el ejercicio de cargos de poder político, eran concebidos como masculinos.

Este estudio se inscribe en un contexto histórico en el cual, principalmente, la corriente del feminismo liberal emerge como uno de los efectos del republicanismo, en la medida que cuestiona las dicotomías sociales producto de la división esfera pública y esfera privada, y las afirmaciones contradictorias entre los derechos universales de los individuos, al tiempo que justifica la exclusión basada en la diferencia sexual: "El feminismo es la expresión paradójica de esa contradicción en su esfuerzo tanto por lograr el reconocimiento de la 'diferencia sexual' como por declararla irrelevante” (Scott, 2012, p. 215).

En el 'baculazo a la gobernadora' es posible entrever las reivindicaciones del feminismo, movimiento que lucha por la igualdad de derechos para la mujer desde la primera década del siglo Xx. Un feminismo basado en la idea de que lo fundamental para el progreso de la mujer era la igualdad jurídico-formal entre los sexos y, en este caso en particular, que más mujeres ejercieran cargos de poder político, pues ello demostraría que tenían las mismas capacidades que los hombres para gobernar. Este discurso omitía cualquier cuestionamiento a las desigualdades basadas en la diferencia sexual que salieran de este terreno jurídico-formal, es más, en cierto sentido instrumentaliza los imaginarios tradicionales sobre el rol social de las mujeres y los estereotipos de género en la sociedad colombiana del momento. Si bien las mujeres tuvieron la capacidad de acceder a mayores espacios públicos, no por 
ello se cuestiona su papel en la familia. De cualquier modo, en la casa o en la plaza pública, el rol de las mujeres estaba sustentado en el ideal maternalista, según el cual su prioridad debía ser la protección de los hijos. En la mayoría de los casos, ello obstaculizó el propósito de que la mujer aumentara su participación pública en la sociedad o decidiera seguir su curso como "mujer-política". De esta manera, el feminismo de la igualdad, que se encontraba tomando fuerza en medio de la clase política del país en el momento que tuvo lugar el 'baculazo', apareció como un referente negativo, o al menos incómodo, por cuanto su insistencia en la desigualdad basada en la diferencia sexual era representada como un discurso radical y divisionista que iba en contra del ideal de una sociedad en donde hombres y mujeres eran iguales y cuya realización solo requería del reconocimiento jurídico-formal de esa realidad.

El artículo está dividido en tres apartados. En el primero presentamos el contexto relevante para entender el 'baculazo' en el marco más amplio de la historia de la participación política de las mujeres: el tercer cuarto del siglo xx y en el ambiente específico de la reforma del Concordato entre la República de Colombia y la Santa Sede, y las elecciones de 1974, en las cuales jugaron un papel clave, entre otros, los temas del matrimonio civil y el divorcio. En el segundo se examina la disputa entre el discurso de género tradicional y moderno sobre la mujer, que se expresó a partir del nombramiento de Dora Luz Campo y el veto impuesto por los prelados católicos. El argumento que se desarrolla en este apartado es que, ante el veto impuesto por los sacerdotes, el discurso moderno pudo expresar los avances en materia de igualdad jurídicoformal y de acceso de las mujeres a espacios de poder político en la Colombia de la década del setenta. En el tercer aparte se examinan los límites del discurso moderno centrado en la igualdad jurídico-formal, que excluía cualquier cuestionamiento a otras formas de desigualdad basadas en la diferencia sexual. El argumento que se desarrolla en ese punto es que el 'baculazo' mostró que el ideal de la mujer moderna que tenía la posibilidad de acceder a espacios de poder político no solo estaba limitado a cierto tipo de mujeres, sino que estas debían ajustarse 
a un comportamiento social que reforzaba elementos tradicionales de los roles y estereotipos de género asignados a las mujeres, y restringía el tipo de cuestionamientos que podían hacer frente a otras formas de desigualdad basadas en la diferencia sexual.

Las fuentes que usamos para este análisis son las noticias que sobre este episodio aparecieron en tres periódicos — dos de cobertura nacional y uno de cobertura regional-, durante las dos semanas que transcurrieron entre el nombramiento de Dora Luz Campo como gobernadora y el momento en que ella anunció que no aceptaba el cargo. Los dos diarios de cobertura nacional son El Tiempo y El Espectador, de línea editorial liberal, y el diario de cobertura regional El Colombiano, de línea editorial conservadora, y que cubría las noticias de Medellín y Antioquia. ${ }^{2}$ Además, recurrimos a documentos del Archivo General de la Nación (Colombia) y del Departamento de Estado de los Estados Unidos sobre los asuntos internos de Colombia, que resultaron pertinentes para ahondar en el contexto histórico de este episodio.

Es importante anotar que la centralidad de la prensa como fuente para este artículo obedece a que el propósito es captar los imaginarios de género que circularon en la opinión pública en torno al episodio del 'baculazo'. Es decir, más que recuperar lo que decían o percibían las mujeres, interesa lo que se decía sobre las mujeres, en particular, del orden de género al que debían ajustarse aquellas que eran nombradas en altos cargos públicos y que puede ofrecer pistas sobre el caso de las mujeres que se presentaban como candidatas a cargos de elección popular. En cualquier caso, si bien el artículo está centrado en analizar lo que se dice en la prensa sobre lo que era o debía ser la mujer (Perrot, 2009 , p. 15) que entraba a ocupar cargos de poder político, queda pendiente analizar este episodio a partir de la prensa femenina o feminista

2 Los tres periódicos circulan hasta el día de hoy, sin embargo, la caracterización de su línea editorial hace referencia a la que presentaban en 1975; no se determina si aún la mantienen. 
de la época, así como de la historia oral, en la medida que ello posibilitaría captar también la manera en que las mujeres interpretaron y percibieron este episodio. ${ }^{3}$

\section{Participación política de la mujer e igualdad jurídico- formal entre los $\operatorname{sexos}^{4}$ en la segunda mitad del siglo $\mathrm{Xx}$ en Colombia}

El contexto más amplio en el que se desarrolló el episodio del 'baculazo' estuvo marcado por las presiones por una mayor participación de las mujeres en cargos públicos ${ }^{5}$ tanto de elección popular como por nombramiento, y los debates en torno al matrimonio civil y el divorcio que se dieron en el proceso de reforma al Concordato de 1887, que tuvo lugar entre 1973 y $1974 .{ }^{6}$ Además, es necesario tener en cuenta que la elección presidencial de 1974 tuvo dos particularidades. Por un lado, como lo señalaba un funcionario de la Embajada de Estados Unidos, era la primera elección presidencial en la historia el hemisferio occidental (White, 1973, p. 6) en la que una mujer aspiraba a dicho cargo,

3 Para ahondar en el papel de prensa producida por mujeres durante el siglo xx en Colombia, ver: http://pasadoimpreso.uniandes.edu.co/mujeres-de-prensa

4 El término empleado aquí hace referencia al lenguaje utilizado en los proyectos de ley para otorgar a las mujeres iguales derechos en la participación política en los años 70 en Colombia. El debate sobre el uso de categorías como "sexo” para designar la construcción cultural sobre la genitalidad masculina o femenina, no se agota en este artículo, pero tampoco hacemos un uso del término de forma ingenua. Para mayor detalle consultar el libro Sexo, género y feminismo: tres categorías en pugna, de Gabriela Castellanos.

5 Esta presión se dejó ver en diversos episodios. Por ejemplo, en abril de 1963, la Embajada de los EE. UU. en Colombia informaba al Departamento de Estado de su país que, en respuesta a las presiones que había recibido para nombrar más mujeres en cargos públicos, el presidente Guillermo León Valencia había creado 50 cargos diplomáticos de segundo rango, en 32 de los cuales nombró mujeres; sin embargo, anotaba el mismo documento, la medida había generado rechazo entre las mujeres nombradas porque ninguna fue designada embajadora (Joint Week A, 1963).

6 El nuevo Concordato entre el Estado colombiano y la Santa Sede fue firmado en julio de 1973; el Senado lo aprobó en diciembre del mismo año y de ahí pasó a la Cámara, corporación que lo aprobó en diciembre de 1974, luego de lo cual fue sancionado como la Ley 20 de 1974 (El Tiempo, 1973c, p. 6A; 1973i, p. 14A y 1974b, p. 6A). 
refiriéndose a María Eugenia Rojas, candidata presidencial por la Alianza Nacional Popular (ANAPO). Por el otro, fueron las primeras elecciones, desde 1958, sin la alternancia presidencial impuesta por el Frente Nacional (Duque Daza, 2019, p. 125), las últimas en las que coincidieron las elecciones presidenciales y legislativas y, además, las únicas en las que los tres candidatos más opcionados eran hijos de expresidentes: María Eugenia Rojas (ANAPO), Álvaro Gómez Hurtado (Partido Conservador) y Alfonso López Michelsen (Partido Liberal) (Pécaut, 2006, p. 203). ${ }^{7}$

Aunque la campaña presidencial de 1974 estuvo centrada en temas económicos debido a la creciente inflación, varios temas relacionados con las mujeres también emergieron a lo largo de la campaña no solo por la candidatura de Rojas, sino además por el esfuerzo que hizo el candidato López Michelsen por atraer a las mujeres votantes. En efecto, este último recurrió a dos estrategias para tratar de captar más votos de mujeres. Primero, creó el Comité de Mujeres Liberales coordinado por María Elena de Crovo - quien luego fue nombrada ministra de Trabajo por el presidente López Michelsen- y, segundo, por medio de propuestas puntuales para mejorar la condición de la mujer en la sociedad colombiana, tales como presionar a la Cámara para que aprobara el nuevo Concordato firmado en $1973,{ }^{8}$ presentar al Congreso los proyectos de estatuto de igualdad jurídica entre los sexos y de divorcio civil, y la promesa de aumentar la participación de mujeres en su gabinete y en los cargos que dependían del Poder Ejecutivo, como era el caso de las gobernaciones, alcaldías y otras instituciones públicas (Villarreal, 1994, pp. 166-167; Wills, 2004, pp. 163-164; Harkess y Pinzón, 1975, p. 439; El Tiempo, 1973g, p. 4A; Vaky, 1974, RG 59).

7 Los otros dos candidatos fueron: Hernando Echeverry Mejía por la Unión Nacional de Oposición (UNO) y Hermes Duarte por la Democracia Cristiana (Pécaut, 2006, p. 203).

8 El divorcio fue un tema central en la reforma al Concordato, pues si se derogaba la Ley Concha y se autorizaban los matrimonios civiles sin necesidad de que los católicos abjuraran de su fe, se abría la posibilidad de aprobar el divorcio civil, ello en opinión de políticos como López Michelsen, y a lo cual se oponían varios jerarcas de la Iglesia, como el entonces obispo de Pereira, monseñor Castrillón Hoyos (Valencia, 1973, p. 6A; Abad, 1973, p. 5A; El Tiempo, 1973f, p. 12A). 
La apelación a la participación de las mujeres en las campañas políticas no era un tema novedoso. Desde 1957, cuando las mujeres ejercieron por primera vez su derecho al sufragio, las élites políticas habían hecho un esfuerzo por atraerlas a las urnas. Las elecciones de 1957 fueron particulares porque se trató de un plebiscito que, si bien tenía como objetivo principal refrendar el pacto político del Frente Nacional, también sirvió para reafirmar el derecho al sufragio femenino, que había sido instituido en 1954 por la Asamblea Nacional Constituyente (ANAC) durante el gobierno de Rojas Pinilla (Sastoque y Pérez, 2020, pp. 76-77; Velásquez, 1989, pp. 58-59). En marzo de 1958, en el marco de las primeras elecciones legislativas que tuvieron lugar tras la caída de Rojas Pinilla, las élites del Frente Nacional apelaron a las mujeres en su papel de sufragantes, no como candidatas. Al respecto, en una carta fechada el 21 de mayo de 1959, dirigida al entonces presidente Lleras Camargo, Ofelia Uribe de Acosta le explicaba que la poca presencia de las mujeres en las listas liberales no se debía a su pasividad, como lo sugería el mandatario, sino a que votaron disciplinadamente por las listas recomendadas por los jefes políticos y, que si no habían presionado por mayor representación, era porque querían evitar generar tensiones en momentos en que apenas se estaba afianzando la restitución de las instituciones democráticas. Sin embargo, anotaba Uribe de Acosta, ante la sorpresa que les produjo las listas elaboradas, "las mujeres nos reunimos para organizar el movimiento de Acción Femenina Liberal (...) cuyas actividades se han dirigido a obtener la representación que en justicia nos corresponde” (1959).

En esa carta, Uribe de Acosta también refutó la versión de Lleras Camargo según la cual, en Colombia, el derecho al sufragio femenino no había sido el producto de movilizaciones por parte de las mujeres, sino más bien una consecuencia de las luchas sufragistas en Europa y Estados Unidos, razón por la cual las colombianas carecían de experiencia y conocimientos para ejercer los cargos que ahora se les abrían ante sí. Frente a ello, Uribe de Acosta (1959) anotaba que si bien era cierto que el derecho al voto había sido otorgado en parte por la presión ejercida por el general Rojas Pinilla sobre la ANAC, también lo era que, al 
menos desde la década de 1930, un decidido grupo de mujeres habían exigido el reconocimiento de ese y otros derechos.

En efecto, en 1930, cuando se inició el periodo denominado la República Liberal debido a que tras 44 años de dominio conservador el Partido Liberal regresó al poder (Melo, 2017, p. 198), se empezaron a debatir diversos temas que afectaban a la mujer colombiana. Ello abrió un ciclo de reformas que comenzó con el reconocimiento, en 1932, de los derechos civiles de las mujeres casadas, prosiguió en 1933 con una ley que las habilitó para acceder a todos los niveles educativos y continuó con la aprobación, en 1936, de una extraña figura jurídica que, sin reconocerles la ciudadanía o el derecho al sufragio, las habilitaba para ejercer cargos públicos (Velásquez, 1989, pp. 48-50 y 52; Wills, 2004, pp. 92-93). Finalmente, en 1945, el Congreso otorgó la ciudadanía a las mujeres mayores de 21 años, pero negándoles el derecho a elegir y ser elegidas (Velásquez, 1989, pp. 48-50 y 52; Wills, 2004, pp. 92-93). No obstante, la concepción feminista del divorcio como derecho, así como el derecho a la educación, la propiedad personal y el acceso a un nivel de ciudadanía de primera clase, fueron el resultado de los debates que diversas organizaciones de mujeres venían adelantando a nivel mundial, en escenarios como la Comisión Interamericana de Mujeres, creada en La Habana, Cuba, en 1928, y a nivel nacional a partir de la puesta en marcha de la Liga de Acción Feminista Colombiana o la Unión Femenina de Colombia, asociaciones que abanderaron las nombradas reivindicaciones (Velásquez y Reyes, 1995, p. 234).

Aunque limitados, los avances en materia de derechos de las mujeres fueron en parte posibles por las múltiples y diversas organizaciones femeninas que se crearon en ese periodo y que, entre otras cosas,

9 La Unión Femenina de Colombia se creó en 1944 como una organización gremial y suprapartidista para presionar ante el Poder Legislativo reformas favorables a las mujeres. También en 1944 inició la circulación de la revista Agitación Feminista, a cargo de Ofelia Uribe, líder sufragista que ese mismo año incursionó en la radio para propagar sus propuestas. En el Partido Socialista, Lucila Rubio de Laverde impulsó la creación de la Alianza Femenina de Colombia, que convocó a la Primera Conferencia Nacional de Mujeres (Velázquez, 1989, pp. 50-51). 
presionaron a los distintos gobiernos liberales para que los cumplieran y adhirieran a los convenios internacionales que buscaban avanzar en la aprobación de reformas legislativas que mejoraran la situación jurídica de la mujer. ${ }^{10}$ Las reformas aprobadas en este periodo permitieron, en materia de participación política, que algunas mujeres entraran a ejercer cargos públicos, sin embargo, fue hasta el gobierno de Rojas Pinilla que empezaron a ocupar altos cargos en los poderes Ejecutivo y Legislativo, siendo prueba de ello el nombramiento de Josefina Valencia y de Esmeralda Arboleda como constituyentes en la ANAC, lo que les permitió participar en los debates que llevaron a la aprobación del derecho de las mujeres a elegir y ser elegidas. ${ }^{11}$ Empero, debido a que durante el gobierno militar no hubo más elecciones, solo pudieron ejercer su derecho al sufragio en el plebiscito de 1957, lo que se tradujo en una participación histórica, pues desde entonces la abstención femenina empezó a aumentar de forma tal que alarmó a las élites políticas del país. ${ }^{12}$

10 El Gobierno colombiano participó en la VI Conferencia Internacional Americana (La Habana, 1928), donde se creó una comisión para el tema del derecho de las mujeres y que en la VII Conferencia (Montevideo, 1933) se convirtió en la Comisión Interamericana de Mujeres (CIM). En la Conferencia Interamericana sobre problemas de la Guerra y la Paz (México, 1945), Colombia suscribió un documento que recomendaba abolir la legislación discriminatoria en contra de las mujeres y, ese mismo año, en la Conferencia reunida en San Francisco, en la que participó Colombia, también se discutió la necesidad de aprobar la igualdad de hombres y mujeres (Velázquez, 1989, p. 58). Además, en 1952 la cim anunció el inicio de una campaña para demandar plenos derechos para las mujeres, y en Bogotá se reunió un seminario de la ONU para analizar su participación política. Ese mismo año, la onU aprobó un proyecto de Convención Internacional para el reconocimiento de los derechos políticos de la mujer, que entró en vigencia en 1954 (Villarreal, 1994, p. 133).

11 Rojas Pinilla nombró a Josefina Valencia gobernadora y ministra de Educación, y designó a su hija María Eugenia Rojas en la dirección de SENDAS, el principal programa de asistencia social adelantado por el gobierno militar (Velázquez, 1989, p. 58).

12 En el plebiscito de 1957 participó el 56\% de las mujeres habilitadas para votar, cifra que empezó a bajar en elecciones posteriores como lo reflejan los datos de las presidenciales de 1958 (36.6\%), 1962 (25.8\%), 1966 (23.5\%), 1970 (37\%) y 1974 (51.1\%), según estudio de Pinzón y Rothlisberger (1977, p. 52). 
Tras el plebiscito de 1957, no solo empezó un proceso de mayor abstencionismo electoral por parte de las mujeres, sino que además "las redes de militantes que se habían organizado para obtener el sufragio se diluyeron y las mujeres se incorporaron a los partidos como individuos y no como ciudadanas con intereses específicos” (Villarreal, 1994, p. 149). Muchas de las sufragistas que habían jugado un papel importante en la aprobación del voto para las mujeres, se integraron a organizaciones cívico-políticas que sirvieron para articularlas a los movimientos políticos, sobre todo en tareas de socialización y formación política, y coordinando encuentros y actividades de apoyo a los partidos. Una de estas organizaciones fue la Unión de Ciudadanas de Colombia (UCC), creada en 1957 en Medellín por iniciativa del político liberal Alberto Lleras Camargo. ${ }^{13}$ Los comunistas, por su parte, crearon a finales de la década de 1950 la Unión de Mujeres Demócratas (UMD) (Villarreal, 1994, p. 149). Además, los partidos políticos empezaron a crear comités y secretariados para institucionalizar la actividad política de las mujeres, aunque con visiones contradictorias, pues mientras algunos líderes políticos creían necesario incluirlas en los puestos de poder, otros consideraban que su papel debía limitarse a apoyar a los partidos en sus campañas y proyectos políticos. ${ }^{14}$

Ni el derecho al voto ni la institucionalización de la participación de las mujeres en la política tradicional —en organizaciones cívico-políticas o partidistas - lograron transformar los acostumbrados esquemas de acceso a cargos políticos, que para ellas siguieron estando basados en las conexiones familiares con redes políticas, ni tampoco impidieron que las "reivindicaciones feministas desaparecieran casi por completo de la

13 La UCC se creó siguiendo el modelo de la Liga de Mujeres Votantes de EE. UU., idea que propuso Lleras Camargo a Ofelia Uribe, quien se encargó de su conformación (Villarreal, 1994, p. 149).

14 Entre finales de los años 50 y durante los años 60, los partidos tradicionales crearon varias estructuras partidistas de mujeres: Acción Femenina Liberal, Alianza Femenina Liberal, Comité Femenino Liberal, Asociación Femenina Liberal y, por parte de los conservadores, el Comando Nacional Femenino (Villarreal, 1994, p. 152). 
agenda política nacional” (Wills, 2004, p. 98). El peso de las conexiones familiares en el ingreso de las mujeres al mundo político fue un tema constante en los análisis hechos tanto por mujeres que habían jugado un papel importante en el periodo sufragista ${ }^{15}$ como por los estudios académicos que empezaron a aparecer en la década del setenta. ${ }^{16}$ Estas circunstancias llevaron a que la vinculación de las mujeres a la política en el periodo 1958 y 1975 se operara sin cambios profundos en los roles que cumplían y sin autonomía real de decisión, ya que más allá del discurso estatal sobre la modernización de las instituciones políticas no se transformó la subordinación de género y permaneció casi intacto el discurso de la feminidad que cumple con el mandato de los estereotipos de género de la época (Villarreal, 1994, p. 148). En otras palabras, se trató de un proceso de inclusión sin representación (Wills, 2004, p. 137), en el que la designación de algunas mujeres provenientes de familias o círculos sociales de élites políticas en cargos públicos, como en el caso de Dora Luz Campo, significaba un avance en su posición particular o la inclusión de un cuerpo de mujer en instancias de gobierno, mas no necesariamente un proceso de representación política de sus necesidades y sus intereses, con agendas propias o con reivindicaciones provenientes de la relación estrecha con movimientos feministas y sus luchas. Como lo sostiene María Emma Wills (2004, p. 34), "hoy sabemos que un cuerpo de mujer no garantiza ni una sensibilidad de género, ni una posición feminista, ni necesariamente el compromiso de representar políticamente la diferencia femenina”.

El discurso sobre lo femenino se mantuvo en ámbitos y circunstancias en que los miembros de las élites de los partidos tradicionales apelaron

15 Lucila Rubio de Laverde, importante sufragista, anotaba la primacía de los poderes familísticos y de amistad en la designación de mujeres en cargos de representación (citada en Villarreal, 1994, p. 152).

16 En dos estudios sobre la participación política de la mujer, publicados en la década de 1970, las autoras insistieron en la importancia que para el acceso de estas a cargos políticos tenía el vínculo con un hombre político en la familia (Harkess y Pinzón, 1975, p. 447; Pinzón y Rothlisberger, 1977, p. 27). 
a las mujeres de manera instrumental. En lugar de estimular su participación activa en la vida política, se limitaron a invitarlas a que ejercieran su papel como electoras y como elemento pacificador de la sociedad (Velásquez, 1989, p. 59). Al respecto, planteaban que en un ambiente agitado como el que estaba atravesando el país por la violencia, la participación política de la mujer era deseable porque su lealtad estaba con la familia, el hogar y la patria, y no con tal o cual partido (Villarreal, 1994, p. 130). En marzo de 1970 , en un acto de campaña previo a las elecciones presidenciales que tuvieron lugar en abril de ese año, Lleras Camargo pronunció un discurso frente a miles de mujeres en Cali, en el que expresó claramente la concepción que de la participación política femenina tenían sectores de élite del Frente Nacional. Se limitó a pedirles su apoyo al candidato Misael Pastrana, pues el candidato opositor, Rojas Pinilla, no solo contaba con cierto apoyo entre las mujeres, debido en parte a su papel en el reconocimiento del derecho al sufragio femenino, sino además porque para entonces ya el Frente Nacional mostraba signos de desgaste y de creciente apatía por parte de diversos sectores de la sociedad (Palacios, 2012, p. 69).

En su arenga, Lleras Camargo hizo una defensa a ultranza del Frente Nacional y les recordó a las mujeres que si dicho pacto había logrado pacificar y regresar al país a la senda civilista, se debía en parte a su participación activa tanto protestando contra la dictadura de Rojas Pinilla como votando en masa y favorablemente el plebiscito de 1957 (El Tiempo, 1975u, p. 7). Pero desde aquellos años, según Lleras Camargo, las mujeres habían regresado a sus roles tradicionales en el hogar y era necesario que de nuevo acudieran a las urnas para que resolvieran sus problemas de falta de poder y libertad, pues solo el voto les garantizaba la atención a sus problemas y la obtención de la igualdad que tanto buscaban. Ello lo reafirmó explicando que el voto no era para "llevar más mujeres al gobierno, aunque esto sea muy deseable. Es para decidir las grandes cuestiones del gobierno, en abstracto, y no necesariamente encarnada en las personas" (El Tiempo, 1975u, portada y p. 7). 
Esa inclusión sin representación, que reflejaba el discurso de Lleras Camargo, fue el marco en el cual se inscribió la creciente atención que recibieron las mujeres en el contexto de las campañas presidenciales durante la década del setenta, y que estaba basado en el argumento de la paz y en una estrategia de culpa y miedo que iba en detrimento de la posibilidad de que las mujeres buscaran representar sus propios intereses, como quedaba claro cuando personajes de élite, como Lleras Camargo, les pedían que votaran, pero no para llevar más mujeres al gobierno, sino pensando en la necesidad de defender el Frente Nacional (Villarreal, 1994, p. 165). Un mensaje similar envió Josefina Valencia cuando le preguntaron por la candidatura presidencial de María Eugenia Rojas; en su respuesta afirmó que consideraba que el país no estaba "maduro todavía para la presidencia de una mujer". ${ }^{17}$

Por ello, no es extraño que en las elecciones legislativas de 1970 solo resultaran electas 17 mujeres -4 senadoras y 13 representantes-, lo que significó una disminución de 9 curules frente a la legislatura anterior -3 en el Senado y 6 en la Cámara- (Villarreal, 1994, p. 166). Al respecto, en una nota de prensa Lucy Nieto de Samper señalaba como causa de ello que "las ambiciones incontenibles de los varones los cegaron” (1970, p. 20). Líneas más adelante, haciendo referencia al caso de Bertha Hernández de Ospina, esposa del expresidente Ospina Pérez y hasta entonces la única mujer que de forma ininterrumpida había salido electa al Congreso desde 1958, Nieto anotaba que ello "podría servirnos para concluir, que sin el respaldo masculino, la mujer en política no hace verano. Al menos no todavía” (1970, p. 20).

Por su parte, Misael Pastrana, ya como presidente y respondiendo a una promesa hecha a la UCC durante la campaña, creó en su primer año de mandato la Secretaría de Asuntos Femeninos, adscrita a la Presidencia,

17 Para 1973, la entonces senadora Josefina Valencia pertenecía a la Anapo, pero ese año optó por retirarse de dicho movimiento para regresar al conservatismo, igual que lo hicieron otros parlamentarios descontentos porque consideraban que el partido estaba virando hacia el marxismo (Restrepo, 1973, p. 1-B). 
y nombró en su dirección a la mujer que coordinó el Comité Femenino que respaldó su candidatura. ${ }^{18}$ En mayo de 1973, en una ceremonia a la que asistió el entonces obispo auxiliar de Bogotá, monseñor Rubén Buitrago, el presidente creó la Comisión Jurídica y Social de la Mujer (El Tiempo, 1973a, p. 6B). Ese mismo mes, en el marco de la campaña de alfabetización que inició el gobierno en 1973, el Ministerio de Educación creó la oficina coordinadora del año de la alfabetización, a cuya cabeza quedó Dora Luz Campo (El Tiempo, 1973b, p. 6A). Por esa campaña, el Gobierno nacional recibió el premio Mohammad Reza Pahlavi en septiembre de 1973 (El Tiempo, 1973e, pp. portada y 2A), sin embargo, en noviembre de ese año, el Gobierno ordenó descentralizar la campaña de alfabetización y eliminó la oficina que estaba a cargo de Dora Luz Campo (El Tiempo, 1973h, p. 3A).

En las elecciones legislativas de 1974, la participación de las mujeres permaneció estancada, pues para Senado solo salieron electas como principales dos mujeres, Bertha Hernández de Ospina (conservadora) y María Elena de Crovo (liberal) - aunque esta última no ocupó su curul porque fue nombrada ministra del Trabajo por López Michelsen-, y en la Cámara solo aumentaron una curul, pues salieron electas 14 mujeres (Jaramillo, 1974, p. 16A). Estos resultados evidenciaron que si en la legislatura 1970-1974 las mujeres representaron el 2.54\% de los congresistas en el Senado y el $4.29 \%$ en la Cámara, para la legislatura 1974-1978 esta cifra bajó a 0.90\% para el Senado y aumentó a $6.42 \%$ en la Cámara (Pinzón y Rothlisberger, 1977, p. 59). ${ }^{19}$

En las elecciones presidenciales de 1974 el tema de las mujeres volvió a tomar fuerza con la candidatura presidencial de María Eugenia Rojas, quien durante la campaña apeló a un discurso tradicional sobre la mujer centrado en la familia y dejando claro que se identificaba con

18 Esta Secretaría, adscrita a Presidencia, sirvió como órgano de coordinación, consulta y decisión para elegir a las representantes del país ante la ONU y la OEA en los temas de mujeres (Villarreal, 1994, p. 164).

19 Para un análisis detallado de la participación política de la mujer entre 1958 y 1974 , véase Pinzón y Rothlisberger (1977). 
todos los colombianos independientemente de su sexo (Villarreal, 1994, p. 166; Harkess y Pinzón, 1975, p. 456). Como ya se mencionó, Alfonso López Michelsen no solo apeló a las mujeres nombrando a María Elena de Crovo en un puesto clave en su campaña y apoyando la designación de Gabriela Zuleta, entonces representante a la Cámara, como directora alterna del Partido Liberal (El Tiempo, 1973d, p. 17C), sino que además centró parte de sus propuestas en avanzar aquellas reformas legales que, como la sanción del nuevo Concordato, la igualdad jurídica de los sexos y la aprobación del divorcio civil, interesaban a las mujeres (Wills, 2004, p. 164).

El triunfo de López Michelsen en esas elecciones fue arrollador, pues obtuvo el $57 \%$ de los votos, seguido lejanamente por Álvaro Gómez Hurtado con el 32\% y María Eugenia Rojas ${ }^{20}$ con el 9,73\% (Pécaut, 2006, pp. 206-209). Al respecto, en dos encuestas realizadas con posterioridad a dicha elección, la mayoría de los encuestados contestaron que la razón por la que la ANAPO había reducido su caudal electoral (23\%) y María Eugenia Rojas había perdido la elección presidencial $(16 \%)$, era el hecho de que se tratara de una candidata mujer (Pinzón y Rothlisberger, 1977, p. 48).

Una vez electo presidente, López Michelsen nombró a María Elena de Crovo como Ministra de Trabajo y designó a seis mujeres como gobernadoras (El Tiempo, 1974a, p. 6A). Por otro lado, desde un inicio mostró su voluntad de cumplir las promesas hechas a las mujeres, lo que se tradujo en la presión que ejerció para que la Cámara aprobara el nuevo Concordato (Ley 20 de 1974) ${ }^{21}$ y en la promulgación del Decreto 2820 de 1974, conocido como Estatuto de Igualdad Jurídica de los Sexos

20 Aunque perdió las presidenciales, María Eugenia Rojas resultó electa al Concejo de Bogotá (Rodríguez, 1974, portada y 3C).

21 La reforma al Concordato supuso, entre otras cosas, la eliminación de la llamada Ley Concha (1924), la cual establecía el matrimonio civil sólo para los no católicos y exigía que los católicos que quisieran casarse por lo civil apostataran públicamente de su fe. Por su parte, el Estatuto de igualdad jurídica de los sexos equiparó entre mujeres y hombres: la edad de emancipación, la capacidad para dirigir el hogar, para decidir el lugar de residencia, el peso de las relaciones extramatrimoniales en las 
(Romero, 1974, pp. portada y última B). Sin embargo, el tema del divorcio fue más complicado, como quedó claro en el veto de un sector de la Iglesia Católica al nombramiento de Dora Luz Campo como gobernadora, debido a que se había vuelto a casar por lo civil, luego de haberlo hecho por lo católico.

Pese a ello, en 1976 López Michelsen cumplió parcialmente su promesa, pues si bien no se aprobó el divorcio para los matrimonios católicos, sí lo logró para el matrimonio civil. Más allá de sus limitaciones, esa no fue una victoria menor, pues supuso derrotar una posición sostenida con vehemencia por la jerarquía eclesiástica e impidió que en el futuro se vetara el nombramiento de alguna mujer por ser divorciada. ${ }^{22} \mathrm{~A}$ este punto, se entiende que la integración de las mujeres a la política representaba no solo la vinculación de sus "valores femeninos propios" (referidos como capitalizados por las agrupaciones políticas en contienda desde una perspectiva electoral), sino que además las cualidades del otrora "bello sexo" debieron ser parte de las formas de hacer la política desde mujeres y como mujeres, pero sin alejarse de la identidad de género particular y, además, sin superar el modo masculino de competir por la jefatura de los cargos públicos de más alta posición. Es decir, conectando el complejo articulado entre orden de género, a nivel estructural, con las relaciones de género en lo cotidiano.

\section{Las mujeres divorciadas no entran al cielo, ni ocupan cargos de poder político}

El 28 de febrero de 1975, el presidente Alfonso López Michelsen anunció cambios en varias gobernaciones, ya que para ese momento estos

causales de divorcio, el manejo de los bienes del matrimonio y sustituyó el principio de protección y obediencia por el de ayuda mutua (Amézquita, 1977, pp. 289-292).

22 En 1982, el entonces presidente Belisario Betancur nombró como gobernadora de Caldas a Beatriz Londoño de Castaño, quien se había divorciado y vuelto a casar por lo civil. Ante esa situación, el obispo de Caldas intentó vetar el nombramiento de Londoño, sin embargo, el gobierno desestimó la actuación del prelado y sin prestarle mayor atención al asunto la mantuvo en su cargo (Serrano, 2018). 
cargos dependían del Poder Ejecutivo. Según un informe de la Embajada de EE. UU., varias personas en Colombia que habían consultado creían que se trataba de un intento del gobierno por desviar la atención de problemas más serios, en particular, el continuo aumento de la inflación (Vaky, 1975a, RG 59). En un principio, la noticia sobre el relevo en las gobernaciones se centró en el hecho de que, al menos temporalmente, se había roto la paridad política en estos cargos; sin embargo, otro elemento que llamó la atención de la prensa fue que, en ese cambio de gobernadores, López Michelsen retiró a tres de las seis mujeres que había nombrado en esos cargos al inicio de su mandato y entre los nuevos nombramientos que hizo solo incluyó a una mujer: Dora Luz Campo de Botero. De esa manera, como lo anotó la prensa, el número de gobernaciones ocupadas por mujeres pasó de 6 a 4 (El Tiempo, 1975a, p. portada; El Colombiano, 1975a, p. portada; El Espectador, $1975 b$, pp. portada y $5 \mathrm{~A}) .^{23}$

El 2 de marzo de 1975, la noticia sobre el relevo en las gobernaciones tomó otro cariz debido al veto de los obispos de Pereira (capital de Risaralda), Baltazar Álvarez y Darío Castrillón, al nombramiento de Dora Luz Campo. En adelante, la noticia se centró en los argumentos a favor y en contra del veto, y el apoyo a Dora Luz Campo por parte de diversos sectores de la sociedad. El telegrama enviado por los obispos, que fue filtrado a la prensa, aclaraba que el veto se debía a que Dora Luz Campo no cumplía los requisitos morales necesarios para ocupar dicho cargo, "al no ser su comportamiento social y ejemplar para la comunidad cristiana de esta sección del país”, luego de lo cual le pedían al presidente, seguros de que había sido asaltado en su buena fe, que designara a otra persona (El Espectador, 1975c, p. portada). Los

$23 \mathrm{Al}$ inicio de su mandato, López Michelsen nombró mujeres gobernadoras en seis departamentos: Boyacá (Susana Camacho), Caldas (Pilar Villegas), Cauca (Josefina Angulo), Chocó (Dorila Perea), Huila (Olga Duque) y Norte de Santander (Fidelia Villamizar). En febrero de 1975 reemplazó ocho gobernadores, entre ellos a las gobernadoras de Boyacá, Cauca y Huila. Por otra parte, en reemplazo del gobernador de Risaralda, nombró a Dora Luz Campo (El Colombiano, 1975a, portada y 5A). 
párrocos de Pereira y Dos Quebradas (Risaralda) también enviaron una comunicación al presidente apoyando a los obispos y recalcando que el veto emanaba de su preocupación por la inmoralidad reinante, y porque su nombramiento desafiaba las buenas costumbres y la tradición cristiana de ese departamento (El Espectador, 1975c, p. 20A).

El lunes 3, la prensa informó que en sus sermones dominicales los sacerdotes de Risaralda convocaron a sus feligreses a impedir, mediante manifestaciones públicas, la posesión de Campo y amenazaron con suspender los ritos de la Semana Santa si ella se posesionaba (El Espectador, 1975f, p. 8A; El Tiempo, 1975d, p. portada). Entre tanto, representantes de la alta jerarquía eclesiástica justificaron el veto en los principios democráticos que les daban el derecho a opinar sobre cualquier tema, más si era uno en el que ellos eran expertos, como era el caso del matrimonio católico (El Tiempo, 1975i, p. 1B). Por su parte, otros curas plantearon que el problema de fondo era legal, pues siendo indisoluble el matrimonio católico y estando vivo el primer esposo de Campo, su matrimonio civil era nulo, lo cual la inhabilitaba para ejercer cargos públicos de acuerdo a las normas legales que regulaban esos nombramientos (El Espectador, 19751, p. 8A; 1975u, p. 5A).

Con el paso de los días, la Iglesia Católica redujo la intensidad de sus críticas, ya que, si bien insistían en la necesidad de derogar el nombramiento de Campo, aclaraban que no se trataba de una imposición, sino de una respetuosa petición al gobierno para que reconsiderara su decisión (El Espectador, 1975l, p. 8A; 1975q, p. 5A). A ello añadían que no eran fanáticos, que respetaban la vida privada de las personas y que el veto no era religioso, ni siquiera político, sino moral, por cuanto ellos eran los intérpretes de los sectores cristianos del país que veían con preocupación el avance de la relajación moral (El Espectador, 1975i, p. 10A).

Dora Luz Campo fue así convertida en el instrumento del que se valieron los sectores tradicionales para frenar lo que consideraban una peligrosa tendencia que, si antes no habían podido enfrentar, ahora les era posible hacerlo a través de la figura de una mujer a la que buscaban 
impedirle ocupar un cargo de poder, recurriendo para ello al control que aún ejercía la Iglesia sobre el matrimonio. Los roles de género tradicionales asignados a la mujer resultaron ser, en virtud del veto en comento, el medio más eficaz para que estos sectores expresaran un cúmulo de preocupaciones que no les era posible manifestar en otros campos. Lo anterior fue expuesto por el obispo Castrillón:

El país no puede entrar por el camino del desconocimiento de los valores sustanciales que hemos defendido (...) Hemos visto cómo se atacan otros valores cristianos. Hemos estado en un silencio que trata de evitar males mayores, pero cuando este silencio llega a producir desconcierto (...), tenemos que romperlo. Tenemos que protestar por los intentos de comenzar a ablandar la conciencia pública para introducir el aborto. Tenemos que luchar contra todas aquellas cosas que nos llevan a una inmoralidad pública, cuales son estas las de desconocer los valores cristianos más serios del matrimonio. (El Espectador, 1975i, p. 10A).

Desde el mismo día que la prensa informó sobre el veto empezaron a aparecer voces de rechazo a la actitud de la Iglesia, la cual fue tachada por funcionarios del gobierno, exfuncionarios, expertos en derecho y grupos de mujeres, como anacrónica, oscurantista, inquisitorial, retardataria e injustificable (El Tiempo, 1975c, p. 7A). En términos generales, los argumentos para rechazar el veto se basaban, primero, en el derecho al respeto a la vida privada y el fuero interno de las personas, puesto que ello no afectaba el ejercicio de cargos públicos; ${ }^{24}$ segundo, en la defensa del fuero civil del Estado ante la indebida injerencia de la Iglesia, pues aunque era respetable que sus prelados criticaran algún comportamiento social, no por ello podían intervenir en el nombramiento de funcionarios públicos; ${ }^{25}$ tercero, en que el veto iba en contra de la

24 Las posiciones al respecto pueden verse en: El Espectador (1975d, p. 8A; 1975t, p. 5A), El Tiempo (1975c, p. 7-A; 1975b, p. 7A; 1975k, p. 7A; 1975j, p. 7A; 1975p, p. 3A; 1975q, p. 6A).

25 La polémica fue registrada por El Espectador (1975k, p. 10A; 1975i, portada y 10A; 1975u, p. 8A), El Tiempo (1975o, p. 4A; 1975d, pp. portada y 6A; 1975r, p. 4A; 
doctrina del Concilio Vaticano II y la reforma al Concordato que aprobó el matrimonio civil para los católicos y abrió la puerta para aprobar el divorcio civil; ${ }^{26}$ cuarto, en que el veto mostraba la urgencia de que el Congreso de la República aprobara el divorcio civil para que muchos colombianos regularizaran su situación familiar. ${ }^{27}$

La respuesta más fuerte y que condensó los argumentos de quienes rechazaban el veto provino del presidente López Michelsen, quien en un comunicado reproducido en los tres periódicos consultados en este estudio (El Colombiano, 1975b, pp. portada y última página) iniciaba explicando que conocía la situación de Dora Luz Campo, pues era amigo de su primer esposo; que, en cualquier caso, ello no era prueba de un comportamiento social ofensivo; y que si bien entendía que así lo conceptuara la Iglesia, como presidente él no podía permitir que se discriminara a las personas que se apartaran de las normas eclesiásticas, pues ello constituía una invasión indebida en el fuero interno de los ciudadanos. Por último, el presidente aclaraba que si Campo decidía no aceptar el cargo, él no tendría problema en designar a otra persona, pero que lo que no podía hacer era "sentar el precedente discriminatorio de que solamente la persona casada por el rito católico y no divorciada pueda desempeñar cargos públicos en Colombia" (El Colombiano, 1975b, pp. portada y última página) y, además, el matrimonio civil no constituía una ofensa legal.

En términos legales, el argumento de López Michelsen era que, en los debates para reformar el Concordato, había quedado claro que los matrimonios civiles en el extranjero eran válidos hasta tanto una sentencia judicial los anulara, lo cual no era el caso de Dora Luz Campo.

1975f, p. 6A) y Galindo (1975, p. 4A).

26 Reacciones y críticas de corte religioso fueron ventiladas en El Espectador (1975d, pp. portada y 8A); Escribano (1975, p. 5A; El Tiempo (1975b, p. 7A; 1975h, p. 1B).

27 Las discusiones sobre el divorcio motivaron un número significativo de artículos en El Espectador (1975d, pp. portada y 8A; 1975o, p. 5A) y El Tiempo (1975t, p. 7A; 1975n, p. 6A; 1975s, p. 5A; 1975q, p. 6-A). 
Por otra parte, apuntaba dos interrogantes no jurídicos: el primero, que en una ocasión anterior, al nombrar un hombre en un cargo público, algunos prelados le habían hecho llegar reparos a la vida privada del nominado con mucha discreción y sin herir la reputación del acusado, lo que contrastaba con el caso de Dora Luz Campo, "una esposa y una madre, a quien posiblemente el Gobierno ha perjudicado en escogerla, como experta en alfabetización, para que lleve adelante la campaña que se está adelantando por el Gobierno Nacional en Risaralda, como departamento piloto para este experimento" (El Colombiano, 1975b, pp. portada y última página); el segundo interrogante estaba relacionado con que Campo ya había ocupado, en el gobierno anterior, "un cargo desprovisto de poder político”, sin que los prelados hubieran hecho los reparos que ahora esgrimían al ser nombrada gobernadora (El Colombiano, 1975b, pp. portada y última página).

\section{Madre, esposa, atractiva, elegante y moderada: los límites de "la mujer moderna"}

La caracterización que hizo la prensa de Dora Luz Campo y que ella misma reforzó, se centró en destacar ciertas cualidades femeninas acordes con la idea de "mujer moderna" difundida por la época: por un lado, se le representó como una mujer moderada, diplomática y formal, como quedaba claro en la manera en que evitó criticar a los obispos o a la Iglesia durante todo el episodio, planteando que, si bien como católica respetaba la opinión de la curia, la religión no tenía nada que ver con su nombramiento como gobernadora (El Tiempo, 1975q, p. 6A); o como cuando ante la pregunta de si consideraba que el veto había sido una intromisión de la Iglesia respondió que no tenía los conocimientos para debatir esos temas (El Espectador, 1975t, p. 5-A). En la prensa esa actitud fue reconocida como valor que realzaba su feminidad. Por ejemplo, un periodista que le hizo una crónica, destacaba que sus "respuestas fueron cordiales y evasivas, y que los reporteros le reconocieron ser una diplomática hábil” (El Tiempo, 1975g, p. 1B). Más diciente de esa relación entre moderación y feminidad fue otro 
comentario en esa misma crónica, según el cual ella "nunca pierde la dulzura de carácter mientras conversa, viste ropas de tonos suaves, pero elegantes, que realzan su gracia y finura y es simpática y de amables modales” (El Tiempo, 1975g, p. 1B).

Los comentarios sobre su forma de vestir fueron constantes durante el 'baculazo'. En uno de los primeros perfiles de Campo que aparecieron en la prensa, su autor recordaba cómo cuando ella había llegado a vivir a Barranquilla por motivos de trabajo, iba a la oficina "con vestidos elegantes y tacones altos que le daban un aire de funcionaria de las Naciones Unidas, por la atmósfera exitosa que emanaba de ella” (El Espectador, 1975a, p. 5A). Por su parte, en la crónica antes citada, se relataba que por su labor en la campaña alfabetizadora del Ministerio de Educación, Campo tenía un vida social muy activa y en las "boutiques y salones de belleza que frecuenta, se la tiene por una dama elegante, y en los centros nocturnos de lujo que suele frecuentar en compañía de su esposo [ilegible] como una inteligente y extrovertida que mantiene cordiales relaciones con poetas, literatos, pintores y fotógrafos (...), gente de la 'nueva onda'”. (El Tiempo, 1975g, p. 1B).

Esta imagen de mujer moderna muy femenina, también se reflejó en la forma en que la prensa representaba sus credenciales para ejercer el cargo de gobernadora. En efecto, si bien se reconocía que con 29 años era la mujer más joven que llegaba a ocupar un cargo tan alto en el Gobierno nacional, lo cual se sumaba a su nula experiencia en la política, ello era compensado con los estudios que había cursado en los Estados Unidos, ${ }^{28}$ con su cargo en la campaña alfabetizadora del Ministerio de Educación durante el Gobierno anterior, su apoyo a la campaña de Alfonso López Michelsen en la pasada elección y el alto cargo que entonces ocupaba en una cadena de ropa femenina (El Tiempo, 1975c,

28 Respecto a los estudios de Dora Luz Campo hay poca información en las fuentes consultadas. En ellas solo se señala que, antes de su primer matrimonio, estudió administración de empresas y mercadeo en Estados Unidos. 
p. 7A; El Espectador, 1975a, p. 5A). Como lo expresó López Michelsen en su respuesta a los obispos, su decisión de nombrar a Campo como gobernadora de Risaralda se debía a que su principal labor iba a ser la de llevar a cabo un experimento piloto del programa de alfabetización en dicho departamento (El Colombiano, 1975b, pp. portada y última página). Sin embargo, es importante anotar que Gloria Gaitán, entonces representante a la Cámara por Risaralda, en varias ocasiones expresó sus reparos al nombramiento de Campo, pero no por las razones aducidas por los obispos, sino porque consideraba que no estaba preparada para el cargo y porque carecía de sentido ciudadano (El Espectador, 1975j, p. 11A; Vaky, 1975b, RG 59). En cualquier caso, la defensa de Campo se basaba en definirla como una mujer moderna, formada en el exterior, con experiencia en altos cargos en el sector público y privado, cualidades que no dejaban de estar relacionadas con ciertos atributos de feminidad. De cierto modo, el sustento del discurso de "la mujer moderna” se anida en la experiencia de vida de mujeres que, como Campo, logran ingresar a la educación profesional, la mayoría realiza estudios complementarios en el exterior, de raza blanca o blanco-mestiza, con una condición de clase favorable para desarrollar tales estudios, con un capital político entroncado en la tradición familiar en primer grado de consanguinidad o de formación mono-parental, es decir, un sujeto femenino anclado en la intersección de un rol de género, que se encuentra atrapado entre la domesticidad y el servicio a la patria. Algunas mujeres como Ofelia Uribe de Acosta y Esmeralda Arboleda provinieron de entornos sociales parecidos al de Campo, lo que hace que sus logros en participación política estén inherentemente relacionados con las condiciones antes descritas.

Además de su moderación, su elegancia y los atributos relacionados con su experiencia laboral, la representación de la feminidad moderna de Campo fue acentuada con las constantes referencias a su fragilidad. Esta fragilidad emergió cuando la describieron como una "joven menuda, simpática y a quien se le ocurren las más simples expresiones, pero también las más lógicas para definir su situación” (El Espectador, 
1975k, p. 10A). Sin embargo, fue durante los momentos más difíciles del 'baculazo' que su fragilidad alcanzó su máxima expresión. Por un lado, Campo fue representada como una mujer que requería protección, lo cual fue claramente retratado por un periodista cuando, hablando de los detectives que el Gobierno había enviado para protegerla del asedio periodístico, decía que mientras ellos pateaban y empujaban reporteros, "la joven y frágil y transparente mujer se queda mirando al cielo a través de la ventana del cuarto y se queja un poco del dolor que siente en el pulgar en la mano izquierda (...) a tres semanas de habérselo herido con el espejo del baño" (El Espectador, 1975p, p. 5A).

La fragilidad de Campo no solo se expresó en el acompañamiento policial, sino también en las constantes referencias a su estado de salud. Al respecto, un reportaje sobre su regreso a Barranquilla después de haber tenido una reunión con el presidente en Bogotá, la describe como “demacrada, con el cansancio en los ojos, apoyada en los brazos de dos detectives” (El Espectador, 1975n, p. 8A), luego de lo cual citaba a su esposo, quien detallaba que ella estaba muy deprimida, afectada y que incluso una herida que se había hecho hace tres semanas se le había vuelto a abrir (El Espectador, 1975n, p. 8A). Esta descripción fue corroborada tanto por la hermana de Campo, quien dijo que ella se encontraba deprimida, agotada y que un médico la había tenido que ir a ver y le había recetado pastillas para dormir, como por un periodista que hablando del momento en que quedó atrapada en un ascensor mientras escapaba del asedio de los periodistas, decía: "Allí dentro, estampillada contra un rincón, Dora Luz tenía cara trágica. Un par de lágrimas hacían turno para rodar por sus mejillas” (El Tiempo, 1975m, p. 7A).

Por último, otro elemento que vino a reforzar los atributos femeninos de la figura de mujer moderna representada por Dora Luz Campo fue la constante presencia de su entorno familiar. Ello quedó retratado no solo en las declaraciones que en apoyo de ella hicieron su esposo, su padre, un primo, una tía y un tío, sino cuando decidió ir a su reunión con el presidente acompañada de su hermana y sus dos hijos (El Espectador, 
1975p, p. 5A). A la salida de esa reunión Dora Luz Campo se encontró a su exesposo, quien ese día había tenido que ir a la residencia presidencial a una reunión relacionada con una campaña de beneficencia. Como era obvio, los periodistas explotaron dicho encuentro y las portadas de los periódicos fueron ilustradas con la foto de este momento descrito como cordial, y respecto al cual Campo dijo que, si bien no le pareció correcta la manera en que fue manejado por la prensa, agradecía que hubiera ocurrido, pues le permitió mostrar el tipo de relación que tenía con su exmarido (El Espectador, 1975p, p. 5A; 1975g, p. 11A; 1975h, pp. portada y 11A).

$\mathrm{Su}$ apego al ideal de mujer moderna, pero ajustada al rol tradicional de carácter maternal y sostén del hogar, quedó expuesto cuando ella anunció públicamente que desistía de ocupar el cargo debido a que la situación se había hecho insostenible porque sus hijos se estaban viendo afectados. En una nota del siete de marzo, Dora Luz Campo relataba que había mantenido la calma durante todo el episodio del 'baculazo', “pero cuando esto tocó a mis hijos entonces comencé a afectarme, confieso que me dolió demasiado" (El Espectador, 1975p, p. 5A). Luego, el once de marzo, cuando ya había anunciado su renuncia, Campo explicaba que había tomado esa decisión pensando en sus hijos y en el hogar "que he defendido y he hecho siempre respetable" (El Espectador, 1975s, p. última C).

\section{Epílogo}

Como explica Wills (2004, pp. 146-156 y 165), en 1975 la ONU declaró el periodo 1976-1985 como el Decenio de las Naciones Unidas para la Mujer: Igualdad, Desarrollo y Paz, lo cual coincidió en el país con la emergencia de los primeros núcleos de lo que sería el movimiento feminista de la época. Sin embargo, como queda claro en el episodio del 'baculazo', la presencia de la mujer en las instancias de Gobierno de mayor rango apenas lograba coger fuerza. 
Esta situación, aunque un poco inexistente en las esferas de la política tradicional, no fue del todo desapercibida, pues apareció en diversos momentos como un "fantasma” del que tanto el Gobierno como la misma Dora Luz Campo buscaron distanciarse. En efecto, en distintos momentos, Campo dejó claro que ella no consideraba que el 'baculazo' tuviera algo que ver con los movimientos de 'liberación femenina' y de forma explícita se distanció de las 'activistas por la igualdad de la mujer', pues desde su perspectiva, ello no aportaba nada en la medida que no era el sexo, sino las capacidades, lo que definía a las personas (El Espectador, 1975k, p. 10A; El Tiempo, 1975e, p. 11A).

Esto queda más claro si se tiene en cuenta que a lo largo del 'baculazo' Campo recibió el apoyo de diversas organizaciones de mujeres (El Espectador, 1975e, p. 8A; 1975m, p. 8A), sin embargo, cada vez que le preguntaban por ello, su respuesta iba dirigida a recalcar que les agradecía, pero que lo importante de su gestión era que "hombres y mujeres vamos a trabajar con un solo propósito, con el objetivo de salir adelante" (El Tiempo, 1975q, p. 6A). Sin embargo, nada dejaba más claro su distanciamiento frente a esos discursos, que cuando explicaba que, si bien esperaba con su renuncia haber ayudado a la mujer colombiana, "en cuanto a mí, considero que obtuve una victoria porque pude defender a mis hijos. Esta es simplemente la posición de una madre" (El Espectador, 1975t, p. 5A).

Dora Luz Campo dejó entrever, por un lado, la mayor apertura para las mujeres de espacios de poder hasta entonces considerados como masculinos, sin embargo, también mostró el tipo de mujer que podía acceder a altos cargos, y, por otro lado, los límites de esa apertura. En principio, quedó claro que no cualquier mujer podía ocupar cargos políticos o de poder, pues requerían contar con un estatus social del que muy pocas colombianas disfrutaban, tales como el haber estudiado en el exterior, pero, sobre todo, tener conexiones con algún hombre político en el círculo más cercano, pues el nombramiento de Dora Luz Campo obedeció, al menos en parte, a que el presidente López Michel- 
sen era amigo personal de su exesposo. Por otra parte, la representación que hizo de Campo la prensa y que ella misma ayudó a consolidar, daba cuenta de una mujer moderna que ya no debía apegarse a los mandatos más rígidos del ideal femenino tradicional vigilado por la Iglesia, sin embargo, era claro que por más moderna que fuera, esta mujer debía ajustar su comportamiento a una serie de atributos femeninos que se iban adaptando a las condiciones sociales de un país que transitaba, en ese momento, de la tradición a la modernidad, en espacios de representación política y en el ejercicio mismo del poder en cada gobierno.

\section{Referencias}

Abad Gómez, Javier. (3 de agosto de 1973). La iglesia sí tendría que objetar el divorcio civil. El Tiempo, p. 5A.

Amézquita de Almeyda, Josefina. (1977). Condición de la mujer en el derecho de familia. En Magdalena León de Leal (Dir.), La mujer y el desarrollo en Colombia (pp. 273-315). Bogotá: Asociación Colombiana para el Estudio de la Población.

Connel, Raewyn y Pearse, Rebecca. (2018). Género. Desde una perspectiva global. Valencia: Universidad de Valencia.

Duque Daza, Javier. (2019). El Frente Nacional revisitado. Reflexión Política, 21(42), 109-128.

El Colombiano. (1 de marzo de 1975a). Rota la paridad en gobernaciones. El Colombiano. Portada.

El Colombiano. (5 de marzo de 1975b). López responde a la Iglesia. El Colombiano, portada y última página.

El Espectador. (1 de marzo de 1975a). Nueva gobernadora de Risaralda acepta cargo, El Espectador, p. 5A.

El Espectador. (1 de marzo de 1975b). 8 Nuevos Gobernadores: salen tres mujeres y entra una. El Espectador, p. 5A.

El Espectador. (2 de marzo de 1975c). Iglesia de Risaralda veta nombramiento de Gobernadora. El Espectador, pp. 1A y 20A. 
El Espectador. (3 de marzo de 1975d). Reacciones por el veto episcopal. El Espectador, p. 8A.

El Espectador. (3 de marzo de 1975e). Recepción en El Dorado a gobernadora de Risaralda. El Espectador, p. 8A.

El Espectador. (3 de marzo de 1975f). Sermones en misa contra gobernadora, El Espectador, p. 8-A

El Espectador. (4 de marzo de 1975g). Dora Luz se encontró con su primer esposo. El Espectador, p. 11A.

El Espectador. (4 de marzo de 1975h). López se reunió con la gobernadora”, El Espectador, portada y $11 \mathrm{~A}$.

El Espectador. (4 de marzo de 1975i). Polémica político-religiosa por la gobernadora. El Espectador, p. 10A.

El Espectador. (4 de marzo de 1975j). Que continuará el veto dice el obispo Castrillón. El Espectador, p. 11A.

El Espectador. (4 de marzo de 1975k). Reportaje a la gobernadora: "No he violado leyes católicas”. El Espectador, p. 10A.

El Espectador. (5 de marzo de 1975l). El obispo Castrillón precisa las razones del veto. El Espectador, p. 8A.

El Espectador. (5 de marzo de 1975m). Mujeres caleñas apoyan a la nueva gobernadora, El Espectador, p. 8A.

El Espectador. (6 de marzo de 1975n). El esposo de la gobernadora: 'No ha pensado en renunciar al cargo'. El Espectador, p. 8A.

El Espectador. (6 de marzo de 19750). La gobernadora no ha declinado el cargo. El Espectador, p. 5A.

El Espectador. (7 de marzo de 1975p). 'Acepté como un honor, no como un reto'. El Espectador, p. 5A.

El Espectador. (8 de marzo de 1975q). 'Cancelamos este penoso incidente’: Los obispos. El Espectador, p. 5A.

El Espectador. (11 de marzo de 1975r). Dora Luz declinó la gobernación. El Espectador, p. 5A. 
El Espectador. (11 de marzo de 1975s). Dora Luz en busca de la paz y la felicidad. El Espectador, p. última-C.

El Espectador. (11 de marzo de 1975t). Nadie ha perdido ni ganado. El Espectador, p. 5A.

El Espectador. (12 de marzo de 1975u). Nombran gobernadores en Risaralda y Cundinamarca. El Espectador, p. 8A.

El Tiempo. (5 de mayo de 1973a). Creada Comisión Jurídica de la Mujer. El Tiempo, p. 6B.

El Tiempo. (6 de mayo de 1973b). Nueva entrega de cartilla de alfabetización. El Tiempo, p. 6A.

El Tiempo. (13 de julio de 1973c). “Texto del Concordato firmado ayer”. El Tiempo,

El Tiempo. (20 de agosto de 1973d). Habla Gabriela Zuleta: 'La mujer está a la izquierda'. El Tiempo, p. 17C.

El Tiempo. (7 de septiembre de 1973e). Premio de Educación a Colombia. El Tiempo, pp. portada y $2 \mathrm{~A}$.

El Tiempo. (23 de octubre de 1973f). Seré presidente de las dificultades, dice López. El Tiempo, p. 12A.

El Tiempo. (1 de noviembre de 1973g). Editorial: Tarea para la mujer. El Tiempo, p. 4A.

El Tiempo. (2 de noviembre de 1973h). Descentralizan la alfabetización. El Tiempo, p. 3A.

El Tiempo. (20 de diciembre de 1973i). Aprobado Concordato. El Tiempo, p. $14 \mathrm{~A}$.

El Tiempo. (21 de noviembre de 1974a). 'Nadie debe dudar que hay cambio'. El Tiempo, p. 6A.

El Tiempo. (18 de diciembre de 1974b). "Sancionadas amnistía, dietas y concordato". El Tiempo, p. 6A.

El Tiempo. (1 de marzo de 1975a). 8 nuevos gobernadores. El Tiempo, portada. 
El Tiempo. (2 de marzo de 1975b). Critican a los obispos. El Tiempo, p. 7A.

El Tiempo. (2 de marzo de 1975c). Los obispos vetan a gobernadora. El tiempo, p. 7A.

El Tiempo. (3 de marzo de 1975d). El veto a la gobernadora. Amenazan con suspender Semana Santa, El Tiempo, portada.

El Tiempo. (3 de marzo de 1975e). Gobernadora de Risaralda no le teme al baculazo, El Tiempo, p. 11A.

El Tiempo. (3 de marzo de 1975f). Respaldo a la gobernadora” vetada. El Tiempo, p. 6A.

El Tiempo. (4 de marzo de 1975g). La gobernadora es de la nueva onda”. El Tiempo, p. 1B.

El Tiempo. (4 de marzo de 1975h). No confundir vida privada y vida pública. El tiempo, p. 1B.

El Tiempo. (4 de marzo de 1975i). Obispos vs. Gobernadora. 'En una democracia la Iglesia tiene derecho a protestar', El Tiempo, p. 1B.

El Tiempo. (4 de marzo de 1975j). Plebiscito de apoyo a nueva gobernadora. El Tiempo, p. 7A.

El Tiempo. (4 de marzo de 1975k). Tío de la gobernadora se dirige a los obispos. El Tiempo, p. 7A.

El Tiempo. (4 de marzo de 1975l). Dice gobernadora vetada: ...Ni un paso atrás! El Tiempo, p. 1B.

El Tiempo. (5 de marzo de 1975m). Día negro tuvo Dora Luz. El Tiempo, p. 7A.

El Tiempo. (5 de marzo de 1975n). López respalda a gobernadora, pero ella no aceptó el cargo. El Tiempo, p. 6A.

El Tiempo. (6 de marzo de 1975o). Por los fueros del Estado. El Tiempo, p. 4A.

El Tiempo. (6 de marzo de 1975p). Presionan para que acepte gobernadora. El tiempo, p. 3A.

El Tiempo. (7 de marzo de 1975q). Dora Luz se confiesa: "Perdono a todos los que me injuriaron”, El Tiempo, p. 6A. 
El Tiempo. (8 de marzo de 1975r). Carlismo a la criolla. El Tiempo, p. 4A.

El Tiempo. (8 de marzo de 1975s). Villanos en el aire. El Tiempo, p. 5A.

El Tiempo. (12 de marzo de 1975t). Incidente superado. El Tiempo, p. 7A.

El Tiempo. (20 de marzo de 1975u). 'El voto femenino es decisivo': A. Lleras”, El Tiempo, p. 7.

Escribano, Teófilo. (10 de marzo de 1975). Aún se puede rectificar”, El Tiempo, p. 5A.

Galindo, Alberto. (9 de marzo de 1975). Democracia práctica. El Tiempo, p. 4A.

Harkess, Shirley y Pinzón, Patricia. (1975). Women, the Vote, and the Party in the Politics of the Colombian National Front. Journal of Interamerican Studies and World Affairs, 17(4), 439-464.

Jaramillo, Sylvia. (25 de abril de 1974). La liberación femenina no llegó al Congreso. El Tiempo, p. 16A.

Joint Week A N. ${ }^{\circ} 16$ (abril 17 de 1963), [Airgram A-679], RG 59, 1963, Caja 3870, Carp. POL 2-1 2-1-63. National Archives and Records Administration, College Park, Maryland, Estados Unidos.

Lamus Canavate, Doris. (2009). Movimiento feminista o Movimiento de mujeres en Colombia. Ponencia presentada en el Seminario Internacional Mujer con voz la política sí va. Medellín, septiembre 23 y 24.

Lugones, María. (2008). Colonialidad y género. Tabula Rasa, (9), 73-101.

Martino Bermúdez, Mónica de. (2013). Connel y el concepto de masculinidades hegemónicas: notas críticas desde la obra de Pierre Bourdieu. Revista Estudos Feministas, 21(1), 283-300. https://dx.doi.org/10.1590/S0104026X2013000100015

Melo, Jorge Orlando. (2017). Historia mínima de Colombia. México D.F: El Colegio de México-Turner.

Mora, Oliver. (2010). Los dos gobiernos de Alfonso López Pumarejo: Estado y reformas económicas y sociales en Colombia (1934-1938, 1942-1945). Apuntes del Cenes, 29(50), 151-171. 
Nieto de Samper, Lucy. (2 de julio de 1970). Mujeres en el Parlamento ¿Qué hicieron?, ¿Por qué las derrotaron? El Tiempo, p. 20.

Palacios, Marco. (2012). La violencia pública en Colombia. México, D.F.: Fondo de Cultura Económica.

Pécaut, Daniel. (2006). Crónica de cuatro décadas de política colombiana. Bogotá: Grupo Editorial Norma.

Perrot, Michelle. (2009). Mi historia de las mujeres. Buenos Aires: Fondo de Cultura Económica.

Pinzón, Patricia y Rothlisberger, Dora. (1977). Participación política de la mujer. En Magdalena León de Leal (Dir.), La mujer y el desarrollo en Colombia (pp. 29-69). Bogotá: Asociación Colombiana para el Estudio de la Población.

Restrepo, Darío. (30 de noviembre de 1973). 39 parlamentarios se han retirado de la Anapo. El Tiempo, p. 1-B.

Rodríguez, Abel. (24 de abril de 1974). Cómo quedará integrado el Concejo de Bogotá. El Tiempo, pp. portada y 3C0.

Romero, Ángel. (23 de diciembre de 1974). Sorpresa y complacencia por Estatuto de la Mujer. El Tiempo, pp. portada y última B.

Sastoque, Edna Carolina y Pérez, Mauricio. (2020). De la dictadura a la democracia limitada del Frente Nacional (1956-1959): Un caso exitoso de negociación. Bogotá: Universidad Externado de Colombia.

Serrano, Rafael. (2 de diciembre 2018). Vida y obra del Cardenal Emerito de Colombia, Monseñor José de Jesús Pimiento Rodríguez. Diario El Frente, s/p. Disponible en: https://www.elfrente.com.co/web/index.php?ecsmod$\mathrm{ule}=$ frmstasection\&ida $=61 \& i \mathrm{db}=116 \& i d c=31710$

Scott, Joan Wallach. (2003). Género e Historia. México D.F.: Fondo de Cultura Económica/Universidad Autónoma de la Ciudad de México.

Scott, Joan Wallach. (2012). Las mujeres y los derechos del hombre. Feminismo y sufragio en Francia, 1789-1944. Buenos Aires: Siglo XXI Editores.

Semana. (20 de septiembre de 1982). El Monseñor y la gobernadora. Semana, 
Uribe de Acosta, Ofelia. (21 de mayo de 1959). Señor Presidente de la República. [Carta refutando afirmaciones hechas por el presidente Lleras Camargo]. Archivos Oficiales, Presidencia, Secretaría Privada, Partidos Políticos, Caja 32, Carpeta 41. Archivo General de la Nación, Bogotá.

Vaky, Viron P. (8 de abril de 1974). Presidential Campaign. Liberal Candidate Presents his Program. [Memo de la Embajada de EE. UU. en Colombia al Dpto. de Estado de EE. UU. sobre la elección presidencial]. [Registro Electrónico]. RG 59. Disponible en: https://aad.archives.gov/aad/createpdf?rid $=70969 \& \mathrm{dt}=2474 \& \mathrm{dl}=1345$

Vaky, Viron P. (5 de marzo de 1975a). Church confronts president López over proposed new governor [Memo sobre el 'baculazo']. RG 59. Electronic Telegrams. Disponible: https://aad.archives.gov/aad/createpdf?rid $=199096 \& d$ $\mathrm{t}=2476 \& \mathrm{dl}=1345$

Vaky, Viron P. (7 de marzo de 1975b). The week in Colombia. [Memo sobre los acontecimientos políticos de la semana en Colombia]. RG 59. Electronic Telegrams. Disponible en: https://aad.archives.gov/aad/createpdf?rid $=20$ $8265 \& \mathrm{dt}=2476 \& \mathrm{dl}=1345$

Valencia Diago, Gloria. (13 de julio de 1973). Ni divorcio ni matrimonio civil. El Tiempo, p. 6A.

Velázquez Toro, Magdala. (1989). Condición jurídica y social de la mujer. En Álvaro Tirado Mejía, Nueva Historia de Colombia (t. IV, pp. 9-60). Bogotá: Editorial Planeta.

Velásquez Toro, Magdala y Reyes Cárdenas, Catalina. (1995). Proceso histórico y derechos de las mujeres años 50 y 60. En Las Mujeres en la Historia de Colombia (t. I, pp. 229-257). Bogotá: Editorial Norma.

Villarreal, Norma. (1994). Movimientos de mujeres y participación política en Colombia, 1930-1991. En Lola Luna y Norma Villarreal, Historia, género y política: movimientos de mujeres y participación política en Colombia, 19301991 (pp. 59-194). Barcelona: Universidad de Barcelona.

White, s/n (10 de diciembre de 1973). Presidential Campaign. Conversation with ANAPO candidate. [Memo de conversación entre un funcionario de la embajada y María Eugenia Rojas]. NARA, RG 59, 1970-1973, Caja 2209, Carp. POL COL 14 5-1-70, p. 6. 
Wills, María Emma. (2004). Trayectorias femeninas y feministas hacia lo público en Colombia (1970-2000) ¿Inclusión sin representación? (Tesis de doctorado). University of Texas at Austin, Texas. 